\title{
Estratégias de marcação temporal nas Cantigas de Santa Maria
}

Andréa Lourdes Ribeiro

FAMINAS-BH

andrearibeiro2004@yahoo.com.br

\begin{abstract}
Considering the conception of language as an intersubjective activity, this work intends to develop a study concerning the linguistic expression of a given time, in a synchronic period corresponding to the first phase of the Archaic Period of the Portuguese language. Taking a corpus formed by ballads of miracles of the major "troubadourbook" of the Medieval Iberia as reference, the Cantigas de Santa Maria (Saint Mary's Ballads), by D. Afonso X, the various resources used by the author(s) to landmark such temporal category are highlighted and analyzed, taking two main aspects into consideration: the narrative production and the world which is being narrated.
\end{abstract}

KEYWORDS: Cantigas de Santa Maria; galician-portuguese; temporal category.

\section{Introdução}

A questão da temporalidade tem sido objeto de investigação de estudiosos de diferentes áreas, que, desde a Antiguidade, vêm procurando compreendê-la e examinála, à luz de perspectivas próprias a seu campo de pesquisa.

A categoria de tempo configura-se como algo abstrato, como uma forma de sensibilidade totalmente intuitiva, em que as percepções se organizam numa ordem interna, sucessiva, calculada de acordo com a duração dos seres, das coisas e dos acontecimentos.

A análise das formas de expressão do tempo torna-se especialmente interessante nas Cantigas de Santa Maria, códice elaborado por D. Afonso X e sua equipe de Toledo, uma vez que, nelas, é possível identificarmos dois grandes grupos organizados em relação à voz dessa instância de enunciação: as ocorridas no tempo pretérito e as de tempo coetâneo ao do ato enunciativo. Composto de quatrocentos e vinte e sete poemas, o cancioneiro mariano, escrito em galego-português, reúne cantigas de louvor e narrativa de milagres que rememoram os milagres da Virgem Maria, recolhidos de fonte oral ou escrita, "realizados", em sua maior parte, na Europa Medieval, em épocas e espaços variados, em favor de devotos de diferentes classes sociais, de pessoas mais ou menos ligadas à Igreja, de animais, de edificações e até de imagens de Nossa Senhora, muitas vezes desrespeitadas e ameaçadas de destruição por "judeus" e "heréticos". Como não podia deixar de ser, o próprio rei integra o rol de beneficiários da Virgem, configurando-se, discursivamente, como instâncias enunciativa, narradora e referida. 
Para situar as diferentes referências temporais em relação à instância de enunciação, as cantigas do códice mariano empregam diferentes recursos linguísticos responsáveis pela marcação temporal, e revelam estratégias temporais empregadas pelo rei-autor para marcar em suas narrativas em galego-português a proximidade ou a distância temporal dos milagres ocorridos da instância enunciativa, num entrelaçamento entre os tempos cronológico e linguístico.

\section{O tempo em pluridimensão}

Estudado nas diversas áreas científicas, o tempo pode ser analisado sob vários prismas, o que nos demonstra tratar-se de um conceito de natureza pluridimensional. Levando em conta essa multifuncionalidade, Nunes, ${ }^{1}$ em seu estudo sobre o tempo na narrativa, lista e discute as diferentes formas pelas quais ele se reveste, articulando-os à experiência individual e sociocultural dos homens.

Em seus estudos sobre a categoria temporal, Nunes considera dois tipos de tempo: ${ }^{2}$ um "físico", que pode ser medido, quantificado e que tem existência própria independente do ser humano, e um "psicológico", que diz respeito ao tempo vivido, à duração interior de nossos estados internos. Recorrendo a Benveniste (1988), Nunes, ${ }^{3}$ considera, ainda, o tempo "cronológico", "que é o tempo dos acontecimentos, englobando a nossa própria vida". Também como parte desta categoria, de cunho socializado ou público, a ele se engrenam os tempos histórico, litúrgico e político.

No esquema abaixo, temos uma síntese configuracional da taxonomia temporal aqui discutida, que, já se disse, segue de perto a de Nunes: ${ }^{4}$

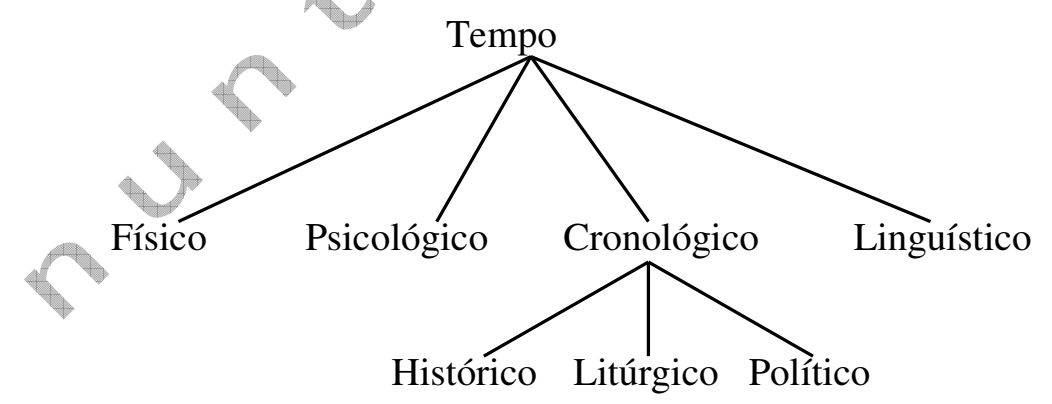

Os estudos sobre o tempo nos remetem à preocupação, vivida por Santo Agostinho, em elucidar os problemas que envolvem a definição dessa categoria: ele

\footnotetext{
${ }^{1}$ Cf. Nunes, B. O tempo na narrativa. São Paulo: Ática, 1995.

${ }^{2}$ Cf. Nunes, op. cit., p. 21.

${ }^{3}$ Cf. Nunes, op. cit., p. 21.

${ }^{4}$ Cf. Nunes, op. cit., p. 18-23.
} 
questiona, no livro XI de suas Confissões, ${ }^{5}$ a sua existência, e tenta analisar a natureza do tempo a partir do espírito humano. Santo Agostinho aponta ainda a dimensão linguística da categoria temporal ao afirmar que a certeza da existência do tempo é testemunhada pela própria linguagem, que nos permite falar a respeito do mesmo em nosso cotidiano, comprovando que ele existe, mesmo que não o saibamos explicar.

Nessa perspectiva, Benveniste, um dos inauguradores da Teoria da enunciação, considera que:

O que o tempo linguístico tem de singular é que está organicamente ligado ao exercício da palavra, definindo-se e ordenando-se como função do discurso. Esse tempo tem seu centro - um centro gerador e axial ao mesmo tempo - no presente da instância da palavra. ${ }^{6}$

Pelo que se pode perceber, o tempo linguístico está diretamente ligado ao exercício da fala, ou seja, ao "agora", ao momento presente do ato enunciativo, que funciona como seu ponto de referência temporal, distinguindo-se do tempo cronológico por possuir divisões próprias, marcadas no ato de execução da fala. A noção enunciativa do tempo foi bem resumida por Nunes, ${ }^{7}$ ao lembrar que a cada vez que alguém fala o faz num tempo presente, permanentemente reinventado, o que revela a "condição intersubjetiva da comunicação linguística".

Se o tempo é concebido a partir de óticas tão distintas, cumpre-nos indagar acerca da existência, ou não, de uma relação entre os conceitos de tempo "cronológico" e "linguístico". Na verdade, eles convergem em determinados aspectos e divergem em outros. O segundo tem, por exemplo, a peculiaridade de ser sempre reinventado a cada nova enunciação e manipulado pelo "agora" do actante enunciador. Dessa sorte, cada ato de fala constitui-se num tempo novo, ainda não experienciado. Ele possui suas próprias divisões, sua própria ordem, que têm a ver com as relações de sucessividade entre estados e transformações representados no texto. Diferentemente, o tempo cronológico, além de suas divisões peculiares, é externo à ação enunciativa e se reporta à duração dos acontecimentos, ancorando-se no mundo real e factual, já referido.

Apesar dessas diferenças, é possível perceber uma ligação entre essas duas faces da mesma instância temporal. A apresentação sistemática dos eventos e dos fatos

\footnotetext{
${ }^{5}$ Cf. Santo Agostinho. Confissões. Tradução de J. Oliveira Santos, S.J., e A. Ambrósio de Pina, S.J. São Paulo: Nova Cultural, 1999 (coleção "Os pensadores").

${ }^{6}$ Cf. Benveniste, E. Problemas de linguística geral I. Campinas: Pontes, 1988, p. 73

${ }^{7}$ Cf. Nunes, op. cit., p. 22.
} 
ocorridos, numa ação narrativa, por exemplo, pode refletir a ordem natural dos acontecimentos do mundo, ou seja, do tempo cronológico. A sua reversão rompe a relação, produzindo efeitos de sentido que variam segundo a intenção autoral.

Uma segunda relação se estabelece entre os dois tempos quando o linguístico necessita ancorar-se no cronológico. Isso ocorre quando a recepção do discurso não é simultânea à sua produção. Nesses casos, advérbios como hoje e agora podem não refletir o momento enunciativo, nem indicar um período preciso. Um meio de obter essa delimitação é o recurso de divisão do tempo cronológico, como, por exemplo, uma determinada data. Lembramos, assim, com Lacey ${ }^{8}$ que a característica mais notável da linguagem temporal é o uso de horas e datas para localizar eventos no tempo com maior precisão.

Essas e outras reflexões de estudiosos servem como evidência da polissemia e da complexidade da categoria de tempo aqui em exame. Vejamos, então, os diferentes recursos linguísticos pelas quais a categoria temporal é marcada nas Cantigas de Santa Maria.

\section{A marcação temporal nas Cantigas de Santa Maria}

Numa análise apurada das Cantigas de Santa Maria, verificamos que a categoria temporal se encontra ricamente explorada e demarcada no códice mariano. Em primeiro lugar, é preciso lembrar que as cantigas resultam do relato de milagres coletados de fonte oral e escrita das maravilhas "operadas" por Nossa Senhora em diferentes cenários, principalmente na Europa Medieval, e em tempos cronológicos distintos, passíveis, às vezes, de identificação indireta.

Se considerarmos com Nunes ${ }^{9}$ que "narrar é desenvolver a experiência humana no tempo" e que "a narrativa abre-nos, a partir do tempo que toca à realidade, um outro que dela se desprende", podemos esperar que as narrativas de milagre de D. Afonso X (re)produzam a linha sucessiva dos fatos ocorridos no tempo real, ou lhe alterem a cronologia por intermédio das variações imaginativas que o discurso (sobretudo artístico) possibilita. Essas diferentes "temporalidades" são percebidas nas narrativas

\footnotetext{
${ }^{8}$ Cf. Lacey, H. M. A linguagem do espaço e do tempo. Tradução de Marcos Barbosa de Oliveira. São Paulo: Perspectiva, 1972, p.52.

${ }^{9}$ Cf. Nunes, op. cit., p. 15.
} 
pelo modo de articulação do enunciador, ou, segundo Ricoeur, ${ }^{10}$ da voz narrativa, que confere aos fatos narrados um tempo coincidente, ou não, com o seu.

\subsection{O tempo em abordagem discursiva}

Rompendo com a tradição de abordagem sistêmica da língua e trilhando o mesmo caminho do pensador russo M. Bakhtin, ${ }^{11}$ Benveniste, juntamente com Jakobson, ${ }^{12}$ foi dos primeiros a tomar em conta, na abordagem da língua, o processo de sua produção, levada a termo intersubjetivamente. Partindo do postulado de que o funcionamento linguístico é determinado por um ato individual, esse autor instaura uma polêmica, ainda em efervescência, que é a questão da subjetividade. No seu modo de ver, antes de acionada pelo ato de enunciação, a língua é apenas uma possibilidade, um instrumento virtual de interação. Atualizada por um sujeito que se aloca num determinado espaço e tempo, ela se constitui em atividade entre um eu que enuncia e um $t u$, que é suscitado pelo $e u$ a uma manifestação de retorno. É nesse processo de atualização verbal que, segundo ele, ${ }^{13}$ aquele que fala se constitui num $e u$ e introduz no discurso a presença de um $t u$, numa interação comunicativa.

Apesar de toda a discussão criada em torno do assunto, não se pode negar que a categoria de pessoa é imprescindível para a efetivação da linguagem em discurso. Obviamente, isso se dá num determinado espaço e tempo, o que nos leva à dedução lógica de que o processo enunciativo se constrói em torno de três categorias: de "pessoa", de "lugar" e de "tempo", conforme mostrado fartamente na literatura específica. Contudo, a ativação das três é assimétrica, uma vez que as categorias de lugar e de tempo estão em relação de dependência direta com o $e u$, que dirige as demais ao situar o seu dizer a partir do local e do momento de sua enunciação, ou seja, do aquiagora. Distinguindo, nos termos de Fiorin, ${ }^{14}$ os planos "enunciativo" (de produção) e “enuncivo" (de produto), conclui-se que o presente enunciativo deve ser visto como um eixo ordenador dos vários tempos compreendidos no discurso, tempos esses detectados a partir de pistas presentes no enunciado.

\footnotetext{
${ }^{10}$ Cf. Ricoeur, P. Tempo e narrativa. Campinas: Papirus, 1995. Tomo II, p. 86.

${ }^{11}$ Cf. Bakhtin, M. Marxismo e filosofia da linguagem. Tradução de Michel Lahud e Yara Frateschi Vieira. São Paulo: Hucitec, 1986.

${ }^{12}$ Cf. Jakobson, R. Lingüística e comunicação. Tradução de Isidoro Blikstein e José Paulo Paes. São Paulo: Cultrix, 1969.

${ }^{13}$ Cf. Benveniste, E. Problemas de lingüística geral II. 3a. ed. - Campinas: Pontes, 1989, p. 73.

${ }^{14}$ Cf. Fiorin, J. L. As astúcias da enunciação. As categorias de pessoa, espaço e tempo. São Paulo: Ática, 1996, p.12.
} 
Tendo em vista que o corpus selecionado para análise se constitui, principalmente, de textos narrativos, considera-se, aqui, nas trilhas de Fiorin, ${ }^{15}$ a realização da enunciação em dois planos mencionados: "enunciativo" e "enuncivo". O primeiro, correspondente à produção do discurso, deixa-se ver no enunciado através de marcações linguísticas próprias (enunciação enunciada), relativas às pessoas (dimensão actorial) eu e $t u$, ao tempo agora e ao espaço aqui. O segundo é reservado à referência, isto é, ao enunciado desprovido de indiciações ligadas ao ato enunciativo, remetendonos, pois, à pessoa ele, ao tempo então e ao espaço algures. A marcação do tempo enunciativo se faz por elementos dêiticos que, para os gregos, se restringiam à classe dos demonstrativos: segundo Lahud, ${ }^{16}$ coube ao pensamento contemporâneo estender ao termo "a noção bastante larga da enunciação", incluindo outras classes que se encaixam nas "expressões referenciais definidas". Nessa esteira de pensamento, tal como Lopes, ${ }^{17}$ considera-se aqui a dêixis como um fenômeno que, atuando na construção da polifonia e da referenciação, constitui enunciadores e alocutários nas instâncias da enunciação, aí instaurando as categorias de tempo e espaço, por si mesmas indiciadoras da dimensão actorial. Por sua vez, no plano enuncivo, a anáfora, cuja existência, segundo Lyons, ${ }^{18}$ pressupõe uma base dêitica, atua na identificação de referentes localizados em outro espaço do texto.

Distinção similar foi feita por Benveniste, ${ }^{19}$ em seus estudos sobre a relação dos tempos no verbo francês, que, segundo ele, se distribuem em dois planos distintos: do discurso e da história. O primeiro pressupõe um eu que instaura um $t u$, utilizando todas as coordenadas espaço-temporais da enunciação; o segundo caracteriza-se por um relato de eventos passados, sem o envolvimento do locutor. Essa diferenciação de planos, referida na seção anterior, tem implicações linguísticas, uma vez que o emissor se vale de estratégias diferentes para marcar o seu ocultamento ou a sua presença, na materialidade do seu dizer.

Pelo que se pode ver, nesse contexto teórico, o sujeito enunciativo é considerado o responsável por projetar no discurso seu tempo e espaço, e também por gerenciar os tempos dos acontecimentos e o espaço dos seres e objetos enunciados, tomando a si próprio como referência básica para o ato enunciativo.

\footnotetext{
${ }^{15}$ Cf. Fiorin, op. cit., p.12-13

${ }^{16}$ Cf. Lahud, M. A propósito da noção de dêixis. São Paulo: Ática, 1979, p. 40.

${ }^{17}$ Cf. Lopes, M. A. O processamento dêitico na constituição da polifonia. Belo Horizonte: PUC- Minas, 1998 (dissertação inédita de mestrado em língua portuguesa), p. 165.

${ }^{18}$ Cf. Lyons, J. Semantics. Cambridge: University Press, 1977. Vol. II, p. 67.

${ }^{19}$ Cf. Benveniste, E. Problemas de linguística geral I. Campinas: Pontes, 1988, p. 47.
} 
Associando essa dupla possibilidade de articulação com o tempo histórico, é possível identificar nas cantigas de milagre dois grandes grupos temporais, organizados em relação à voz narrativa: as cantigas de milagres ocorridos num tempo pretérito ao ato de sua narração e as de tempo coetâneo ao do rei-autor. Para facilitar a referência, chamem-se àquelas de "cantigas de milagre pretérito" e a estas "cantigas de milagre presente".

A marcação temporal organizada a partir do tempo pretérito ao ato da enunciação apresentado pelas "cantigas de milagre pretérito", MRPretérito, pode ser detectada de várias maneiras. Uma delas é a menção explícita ao local de ocorrência do milagre narrado. Para a Hispânia medieval, diz-nos Sousa, ${ }^{20}$ a "sacralidade de um espaço resulta nas peregrinações e romarias a santuários, especificamente aos dedicados a vários santos e à Virgem", peregrinações essas que constituem um "símbolo de vida cristã num esforço de encaminhamento para a vida celeste".

Naturalmente, esse tipo de marcação, no caso, é limitado, uma vez que as localidades mencionadas (muitas das quais tiveram substituídos os seus nomes ou passaram a pertencer a uma nova configuração geopolítica) podem corresponder a períodos de tempo mais ou menos longos, por isso a análise temporal desse recurso merece o devido cuidado do estudioso. A marcação temporal por topônimos é considerada por Fiorin como uma embreagem intercategorial, ${ }^{21}$ ou seja, de uso do espaço pelo tempo. No exemplo que se segue, temos um caso de delimitação temporal através de referência à cidade de Roma, na época do Império Romano, momento este confirmado pela menção à figura do imperador, que aparece como uma das personagens coadjuvantes:

En Roma foi, ja ouve tal sazon, que hũa dona mui de coraçon amou a Madre de Deus; mas enton soffreu que fosse do demo tentada. ${ }^{22}$

Outro tipo de indicação indireta da marcação autorial do tempo pretérito são os antropônimos, o que, segundo Fiorin, ${ }^{23}$ trata-se de embreagem intercategorial de pessoa

\footnotetext{
${ }^{20}$ Cf. de Sousa, L. C. O santuário de Santa Maria do Porto e as romarias medievais nas "Cantigas de Santa Maria”. Belo Horizonte: 1999 (mimeografado - trabalho apresentado no III EIEM - RJ).

${ }^{21}$ Cf. Fiorin, op. cit., p.95.

22 Cf. Cantiga XVII, v. 10-13/ 35-36 (tradução: "Em Roma, aconteceu há muito tempo que uma mulher, que amava de coração a Mãe de Deus, foi tentada pelo demônio".).

${ }^{23}$ Cf. Fiorin, op. cit., p. 54.
} 
por tempo. A menção de personagens públicas como reis, rainhas, nobres, santos e, até, filósofos serve como sinalização do tempo de ocorrência do milagre, uma vez que essas personagens estão ligadas a um recorte temporal mais preciso, que corresponde ao período de sua própria existência. Assim, permeiam os relatos personagens como o imperador Juliano, o Apóstata, referido no primeiro exemplo abaixo, que viveu entre os anos de 331 e 363 d.C., e mestre Libânio, no seguinte, sofista e retórico que viveu entre os anos de 314 e 393 d.C..$^{24}$

Esta é como Santa Maria defendeu a cidade de Cesaira do Emperador Juyão. ${ }^{25}$

Eles assi a lança catando, que creer podian muit'adur, maestre Libano foi chegando, filosofo natural de Sur, ${ }^{26}$

Um terceiro recurso a mencionar na delimitação das cantigas que situam os milagres ocorridos no tempo pretérito ao do ato da narração, consideradas no grupo das cantigas de MRPretérito, é o registro da ocorrência de milagres em tempos coincidentes com o tempo histórico, caso do exemplo seguinte, que nos remete ao fato histórico da tentativa de conquista de Constantinopla também pelo imperador Juliano:

De com'eu escrit'achei, pois que foi de crischãos Constatinobre, un rei con oste de pagãos veo a vila cercar mui brav' e mui sannudo, pola per força fillar por seer mais temudo. ${ }^{27}$

É comum encontrarmos, ainda, nas cantigas que compõem o corpus, expressões adverbiais que registram, de um modo mais indeterminado, a distância temporal entre o

\footnotetext{
${ }^{24}$ Conforme dados da edição crítica de Mettmann (Afonso X. Cantigas de Santa Maria. Edição crítica de Walter Mettmann. Madrid: Clásicos Castalia, 1986-1989, p. 93).

${ }^{25}$ Cf. Cantiga XV, ementa (tradução: "Esta conta como Santa Maria defendeu a cidade de Cesareia das mãos do Imperador Juliano".).

${ }^{26}$ Cf. Cantiga XV, v. 158-161 (tradução: "Observavam eles, assim a lança, fato em que muito dificilmente podiam acreditar, quando o mestre Libânio, filósofo natural da Síria, foi chegando”.).

27 Cf. Cantiga XXVIII, v. 14-21 (tradução: "De acordo com o que achei escrito, depois que Constantinopla já pertencia aos cristãos, um rei, muito bravo e furioso, veio cercar a cidade com um exército de pagãos, para tomá-la pela força e assim ser mais temido”.).
} 
milagre narrado e a ação enunciativa. Nas duas citações logo abaixo, temos mostras desse recurso:

Ond'en Cesaira a de Suria

fez un miragre, á gran sazon

por San Basillo Santa Maria. ${ }^{28}$

Em Roma foi ja ouve tal sazon ${ }^{29}$

Ainda no quinto exemplo dado, é possível detectar o emprego do topônimo, Cesaira a de Suria, como recurso linguiístico para a marcação no tempo pretérito.

Passemos agora a análise das "cantigas de milagre presente", MRPresente, que trazem marcas temporais específicas para remeter o leitor ao tempo coetâneo ao do ato da enunciação, ou seja, do rei-enunciador. Uma dessas estratégias é participação de D. Afonso X como beneficiário dos milagres relatados de Nossa Senhora, participação essa que nos remete, por exemplo, ao seu tempo de infância, a seguir, ou à sua fase adulta, logo abaixo:

E dest'un mui gran miragre vos quero dizer que vi, e pero era meñyo, nenbra-me que foi assi, ca m'estava eu deante e todo vi e oý, que fez [o] Santa Maria, que muitos fez e fará. ${ }^{30}$

Como el Rey Don Affonso de Castela adoeçeu en Bitoria e ouv' hua door tan grande que coidaron que morresse ende, e poseron-lle de suso o livro das cantigas de Santa Maria, e foi guarido. ${ }^{31}$

Outra forma de referência ao tempo coetâneo ao da instância de enunciação é a narração de milagres envolvendo pessoas ligadas ao rei, por parentesco direto ou a serviço. Ilustram-nos isso as cantigas de número duzentos e cinquenta e seis, relativa à cura da rainha D. Beatriz, mãe de D. Afonso; a de número cento e vinte e dois, a

\footnotetext{
${ }^{28}$ Cf. Cantiga XV, v. 14-16 (tradução: "Pelo que em Cesareia da Síria Santa Maria fez, há muito tempo, um milagre em favor de São Basílio".).

${ }^{29}$ Cf. Cantiga XVII, v. 10 (tradução: "Em Roma, aconteceu há muito tempo".).

${ }^{30}$ Cf. Cantiga CCLVI, v. 5 (tradução: "A respeito disso, quero vos contar um milagre muito grande que fez Santa Maria, que muitos fez e fará, e que, embora eu fosse criança, lembro-me ter sido assim, pois eu estava presente e tudo vi e ouvi”.).

${ }^{31}$ Cf. Cantiga CCIX, ementa (tradução: "Esta conta como o Rei Dom Afonso de Castela adoeceu em Vitória e teve uma dor tão forte que acreditaram que dela morresse, e colocaram-lhe em cima o livro das cantigas de Santa Maria, e foi curado”.).
} 
registrar a "ressurreição" de sua irmã Berenguela, que se tornou monja; e a de número cento e quarenta e dois, em que apresenta a salvação de um serviçal do rei:

E tod'est'assi foi feito; e logo, sen outra ren, de todos aqueles maes guariu a Reỹa tan ben per poder da Groriosa, que nada non sentiu en. ${ }^{32}$

Como Santa Maria resucitou hũa infante, filha dun rei, e pois foi monja e mui santa molher. ${ }^{33}$

Como Santa Maria quis gua[r]dar de morte un ome dun rei que entrara por hũa garça en un rio. ${ }^{34}$

Também para a delimitação das cantigas de MRPresente foram empregadas expressões adverbiais dêiticas de acepção temporal, que deixam clara a contemporaneidade entre o evento narrado e o tempo de vida (ou de reinado) de D. Afonso X, conforme ilustrado a seguir nos excertos:

e dest'un miragre vos direi eu que ela fez grande nos dias meus. ${ }^{35}$

E daquest' un miragre fez pouc' á en Catalonna a Virgen Santa Maria $(. . .)^{36}$

Do mesmo modo que no grupo de cantigas consideradas de MRPretérito, nesse, de milagres contemporâneos à época de D. Afonso, encontramos o uso de recursos linguísticos de ordem espacial, funcionando como estratégia de marcação temporal (embreagem intercategorial). Um delas é a menção do santuário de Santa Maria do Porto em Cádiz, que, segundo registros históricos, foi mandado construir por D. Afonso $\mathrm{X}$ no intuito de homenagear Nossa Senhora. Sousa ${ }^{37}$ apresenta um estudo de vinte e quatro cantigas do cancioneiro mariano que registram um "ciclo" de milagres

\footnotetext{
${ }^{32}$ Cf. Cantiga CCLVI, v. 35-37 (tradução: "E tudo isso assim foi feito. E logo, sem demora, pelo poder da Gloriosa, a Rainha foi tão bem curada de todos aqueles males que nada mais sentiu".).

${ }^{33}$ Cf. Cantiga CXXII, ementa [tradução: "Esta conta como Santa Maria ressuscitou uma infanta, filha de um rei (D. Fernando), que depois tornou-se uma monja e santa mulher".].

${ }^{34}$ Cf. Cantiga CXLII, ementa (tradução: "Como Santa Maria quis salvar da morte um servidor de um rei, que entrara num rio para recuperar uma garça".).

${ }^{35}$ Cf. Cantiga XXII, v. 7-8 (tradução: "A propósito disso, um grande milagre eu vos contarei que Ela fez nos meus dias".).

${ }^{36}$ Cf. Cantiga XLVIII, v. 6-7 (tradução: "E a propósito disso, a Virgem Maria fez, há pouco tempo, um milagre na Catalunha”.).

${ }^{37}$ Cf. Sousa, op. cit., p. 89
} 
acontecidos neste local, as quais nos remetem, mais fortemente, ao rei-autor e ao momento histórico de luta contra os árabes. A cantiga número trezentos e vinte e oito, cuja ementa se transcreve abaixo no primeiro exemplo, conta-nos a escolha e a determinação por parte da Virgem do lugar em que D. Afonso $X$ deveria erguer o templo em sua homenagem. Já os dois excertos seguintes também ilustram em suas ementas alguns dos milagres acontecidos por intercessão de Nossa Senhora em seu próprio santuário em Santa Maria do Porto:

Esta é como Santa Maria fillou un logar pera si eno reino de Sevilla e fez que lle chamassen Santa Maria do Porto. ${ }^{38}$

Como Santa Maria do Porto mostrou per sa vertude un logar u jaziam muitos cantos lavrados, que meteron ena sa ygreja. ${ }^{39}$

Como Santa Maria do Porto guardou.XXX. omees que cavavan terra pêra sa ygreja, e caeu ua forre sobr' eles e non lles enpeeçeu. ${ }^{40}$

O exame empreendido revelou que, para situar as diferentes referências temporais em relação à instância de enunciação, foram empregadas nas cantigas recursos linguísticos diversificados, responsáveis por revelar as estratégias temporais empregadas pelo rei-autor para aproximar ou distanciar o tempo da narrativa da instância de enunciação, muitas vezes, num entrelaçamento claro entre os tempos cronológico e linguístico.

\section{Considerações finais}

Como se pode observar, os poemas narrativos que compõem as Cantigas de Santa Maria articulam diferentes estratégias para marcar o tempo, os quais possibilitaram a esta análise dividir o corpus em dois grandes grupos: as cantigas ocorridas no tempo pretérito ao do ato da narração, MRPretérito; e as que ocorreram no tempo coetâneo ao do ato da narração, MRPresente.

\footnotetext{
${ }^{38}$ Cf. Cantiga CCCXXVIII, ementa (tradução: "Esta conta como Santa Maria tomou um lugar para si no reino de Sevilha e fez que o chamassem de Santa Maria do Porto".).

${ }^{39}$ Cf. Cantiga CCCLVIII, ementa (tradução: "Esta conta como Santa Maria do Porto mostrou, por sua virtude, um lugar onde se encontravam muitas pedras lavradas, que foram usadas na construção da Sua igreja".).

${ }^{40}$ Cf. Cantiga CCCLXIV, ementa (tradução: "Esta conta como Santa Maria do Porto salvou trinta homens que cavavam terra para a construção da Sua igreja, e ao cair-lhes uma torre não os atingiu".).
} 
A marcação temporal efetuada por recursos diversos que vão da categoria espacial (topônimos) à pessoal (antropônimos), inclui também referências, explícitas ou não, a feitos históricos, menções ao rei-enunciador como personagem e a apresentação de pessoas ligadas diretamente a D. Afonso X. O exame do corpus apontou que:

a. a narrativa dos milagres não se circunscreve ao ficcional, mas tem um "pé" na história, uma vez que articula o mundo real (no caso, de cunho sagrado) e o imaginário;

b. a ancoragem no mundo real tem consequências para a esfera temporal, na qual se divisam manifestações do tempo cronológico (externo), com referências de cunho histórico, religioso e litúrgico;

c. a representação dos conceitos desse tempo externo se processa, quase sempre, de um modo indireto, ou seja, por embreagem, em que cenários, (categoria de espaço) e nomes de personagens (categoria de pessoa) atuam como identificadores do tempo de realização dos milagres.

A investigação realizada por esse trabalho nos oferece resultados parciais acerca do tratamento conferido ao tempo em obra de tal envergadura e valor. Com a pequena contribuição que aqui me foi possível oferecer, espero despertar o interesse de novos pesquisadores por esse trabalho poético, musical e pictório, realizado por um rei em fervorosa homenagem à Virgem Maria.

\section{Referências}

AFONSO X. Cantigas de Santa Maria. Edição crítica de Walter Mettmann. Madrid: Clásicos Castalia, 1986-1989.

BAKHTIN, M. (1929). Marxismo e filosofia da linguagem. Trad. Michel Lahud e Yara Frateschi Vieira. São Paulo: Hucitec, 1986.

BENVENISTE, E. Problemas de linguística geral I. Campinas: Pontes, 1988.

E. Problemas de linguística geral II. Campinas: Pontes, 1989. 
FIORIN, J. L. As astúcias da enunciação. As categorias de pessoa, espaço e tempo. São Paulo: Ática, 1996.

JAKOBSON, R. Lingüística e comunicação. Trad. Isidoro Blikstein e José Paulo Paes. São Paulo: Cultrix, 1969.

LACEY, H. M. A linguagem do espaço e do tempo. Tradução de Marcos Barbosa de Oliveira. São Paulo: Perspectiva, 1972.

LAHUD, M. A propósito da noção de dêixis. São Paulo: Ática, 1979.

LYONS, J. Semantics. Cambridge: University Press, 1977. Vol. II.

LOPES, M. A. O processamento dêitico na constituição da polifonia. Belo Horizonte: PUC-Minas, 1998 (dissertação inédita de mestrado em língua portuguesa).

NUNES, B. O tempo na narrativa. São Paulo: Ática, 1995.

RICOEUR, P. Tempo e narrativa. Campinas: Papirus, 1995. Tomo II.

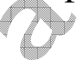

SANTO AGOSTINHO. Confissões. Tradução de J. Oliveira Santos, S.J., e A. Ambrósio de Pina, S.J. São Paulo: Nova Cultural, 1999 (coleção "Os pensadores”).

de SOUSA, L. C. O santuário de Santa Maria do Porto e as romarias medievais nas "Cantigas de Santa Maria”. Belo Horizonte: 1999 (mimeografado - trabalho apresentado no III EIEM - RJ). 